Article

\title{
Increased Expression of 11 $\beta$-Hydroxysteroid Dehydrogenase Type 1 Contributes to Epidermal Permeability Barrier Dysfunction in Aged Skin
}

\author{
Beom Jun Kim ${ }^{1} \oplus$, Noo Ri Lee ${ }^{1}$, Chung Hyeok Lee ${ }^{1}$, Young Bin Lee ${ }^{1}$, Sung Jay Choe ${ }^{1}$, Solam Lee ${ }^{1}$, \\ Hyun Jee Hwang ${ }^{1}$, Eunjung Kim ${ }^{1}$, Gareth G. Lavery ${ }^{2}$, Kyong-Oh Shin ${ }^{3}$, Kyungho Park ${ }^{3}$ and Eung Ho Choi ${ }^{1, *(D)}$ \\ 1 Department of Dermatology, Yonsei University Wonju College of Medicine, Wonju 26426, Korea; \\ kimbeomjun11@naver.com (B.J.K.); noorie00@naver.com (N.R.L.); nitr_o@naver.com (C.H.L.); \\ lyb032@naver.com (Y.B.L.); wow8561@naver.com (S.J.C.); esolami@naver.com (S.L.); \\ 01181129@hanmail.net (H.J.H.); hyksuj0326@naver.com (E.K.) \\ 2 Institute of Metabolism and Systems Research, College of Medical and Dental Sciences, \\ University of Birmingham, Birmingham B15 2TT, UK; g.g.lavery@bham.ac.uk \\ 3 Department of Food Science and Nutrition, Convergence Program of Materials Science for Medicine and \\ Pharmaceutics, Hallym University, Chuncheon 24252, Korea; 0194768809@hanmail.net (K.-O.S.); \\ hopark78@gmail.com (K.P.) \\ * Correspondence: choieh@yonsei.ac.kr; Tel.: +82-33-748-2650
}

\section{check for} updates

Citation: Kim, B.J.; Lee, N.R.; Lee, C.H.; Lee, Y.B.; Choe, S.J.; Lee, S.; Hwang, H.J.; Kim, E.; Lavery, G.G.; Shin, K.-O.; et al. Increased Expression of $11 \beta$-Hydroxysteroid Dehydrogenase Type 1 Contributes to Epidermal Permeability Barrier Dysfunction in Aged Skin. Int. J. Mol. Sci. 2021, 22, 5750. https://doi.org/ $10.3390 /$ ijms 22115750

Academic Editor: Philip W. Wertz

Received: 27 April 2021

Accepted: 21 May 2021

Published: 27 May 2021

Publisher's Note: MDPI stays neutral with regard to jurisdictional claims in published maps and institutional affiliations.

Copyright: (c) 2021 by the authors. Licensee MDPI, Basel, Switzerland. This article is an open access article distributed under the terms and conditions of the Creative Commons Attribution (CC BY) license (https:// creativecommons.org/licenses/by/ $4.0 /)$.
Abstract: Inactive cortisone is converted into active cortisol by $11 \beta$-hydroxysteroid dehydrogenase type 1 (11 $\beta$-HSD1). Excessive levels of active glucocorticoids could deteriorate skin barrier function; barrier impairment is also observed in aged skin. In this study, we aimed to determine whether permeability barrier impairment in the aged skin could be related to increased 11 $\beta$-HSD1 expression. Aged humans $(n=10)$ showed increased cortisol in the stratum corneum (SC) and oral epithelium, compared to young subjects $(\mathrm{n}=10) .11 \beta-H S D 1$ expression (as assessed via immunohistochemical staining) was higher in the aged murine skin. Aged hairless mice (56-week-old, $n=5$ ) manifested greater transepidermal water loss, lower SC hydration, and higher levels of serum inflammatory cytokines than the young mice (8-week-old, $\mathrm{n}=5)$. Aged $11 \beta$-HSD1 knockout mice $(\mathrm{n}=11)$, $11 \beta$-HSD1 inhibitor (INHI)-treated aged wild type $(\mathrm{WT})$ mice $(\mathrm{n}=5)$ and young WT mice $(\mathrm{n}=10)$ exhibited reduced SC corticosterone level. Corneodesmosome density was low in WT aged mice $(n=5)$, but high in aged 11ß-HSD1 knockout and aged INHI-treated WT mice. Aged mice exhibited lower SC lipid levels; this effect was reversed by INHI treatment. Therefore, upregulation of $11 \beta-$ HSD1 in the aged skin increases the active-glucocorticoid levels; this suppresses SC lipid biosynthesis, leading to impaired epidermal permeability barrier.

Keywords: barrier function; skin aging; 11-beta-hydroxysteroid dehydrogenase type 1; glucocorticoids; epidermal lipids

\section{Introduction}

Various physiological parameters in aged skin, including structure, wound healing ability, immune function, and metabolism, show changes compared to those in young skin [1-5]. In addition, the skin barrier function reportedly deteriorates with an increased surface $\mathrm{pH}$, leading to impaired skin integrity and cohesion and delayed barrier recovery, due to the reduction of epidermal lipid synthesis [6-8]. These characteristics of the aged skin are similar to the changes caused by excessive endogenous or exogenous glucocorticoid (GC) levels [2]. Apart from the topical GC administration-induced increase in the local GC concentration, systemic GC accumulation (e.g., in Cushing syndrome or psychological stress) could also trigger such changes [9-11]. Moreover, different types of stresses (not only psychologic, but also physiologic and physical stress) and stress-associated increase 
in GC levels reportedly play an important role in skin homeostasis and various skin diseases $[12,13]$.

Excessive GC levels suppress skin barrier function through mechanisms such as the inhibition of keratinocyte proliferation and differentiation or the suppression of epidermal lipid synthesis [9]. Therefore, physiological changes in the aged skin might be associated with the increase of the active GC level [2,14-16].

Cortisol, an active GC in the human blood, is mainly generated in the adrenal cortex upon the stimulation of the hypothalamic-pituitary-adrenal (HPA) axis. The skin is also known to act as an endocrine organ equivalent to the HPA axis [17-22]. GCs could be synthesized from cholesterol in the skin [23,24]. The de novo local cortisol production pathway involves 11 $\beta$-hydroxysteroid dehydrogenase type 1 (11ß-HSD1); this enzyme converts inactive cortisone to active cortisol, which is expressed in several tissues including the skin, liver, kidneys, large intestine, bone, skeletal muscle, and adipose tissue [25-28]. The local GC level is predominantly regulated via the activity of 11ß-HSD1 [29]. This enzyme is believed to participate in skin homeostasis through the regulation of the endogenous GC levels [30-32] and has been implicated in delayed wound healing and the inhibition of keratinocyte proliferation and differentiation.

The skin is always exposed to physical or chemical irritants; these irritants affect aged skin to a larger extent due to its reduced barrier function compared to the young skin. Local GC activation may be important for controlling local stressors in the irritation-susceptible aged skin. The 11 $\beta$-HSD1 level is known to increase with aging and wound healing [15,33], and this phenomenon may represent a mechanism underlying GC activation in response to aging-induced epidermal stress. This mechanism is a possible explanation for the decreased prevalence of atopic dermatitis (a representative inflammatory skin disease) [34] and the increased prevalence of contact dermatitis and xerotic eczema in the elderly $[35,36]$. Recently, we have reported that $11 \beta-H S D 1$ is a major factor that affects the pathophysiology of atopic dermatitis via the suppression of atopic inflammation through the modulation of active GC levels in the skin [37]. Several studies report on the effects of 11 $\beta$-HSD1 on GC upregulation and skin aging. The suppression of $11 \beta-H S D 1$ expression reduces the cutaneous adverse effects of excessive GC levels and reverses the aging-induced alterations of skin functions [2,38-40].

Therefore, we hypothesized that increased 11 $\beta-H S D 1$ expression and the subsequent increase in the GC levels contribute to the deterioration of barrier function in the aged skin. We tested this hypothesis by analyzing the influence of $11 \beta$-HSD1-mediated regulation of the endogenous GC levels on the barrier function of the aged skin.

\section{Results}

2.1. Stratum Corneum (SC) and Oral Epithelium Cortisol Levels Are Higher in the Aged Participant

The age of the participants in the young and old groups were $21.6 \pm 1.89$ and $65.9 \pm 4.10$ years (mean $\pm \mathrm{SD}, p<0.001$ ), respectively. The cortisol level in the SC collected from the forearms was significantly higher in the aged group than in the young group $(2.604 \pm 0.3438$ vs. $2.139 \pm 0.3359 \mathrm{ng} / \mathrm{mg}, p<0.001)$. In addition, significantly higher cortisol levels were detected in the buccal mucosa epithelium of the aged group than in that of the young group $(2.252 \pm 0.4250$ vs. $1.988 \pm 0.2183 \mathrm{ng} / \mathrm{mg}, p=0.018$; Figure 1$)$. 

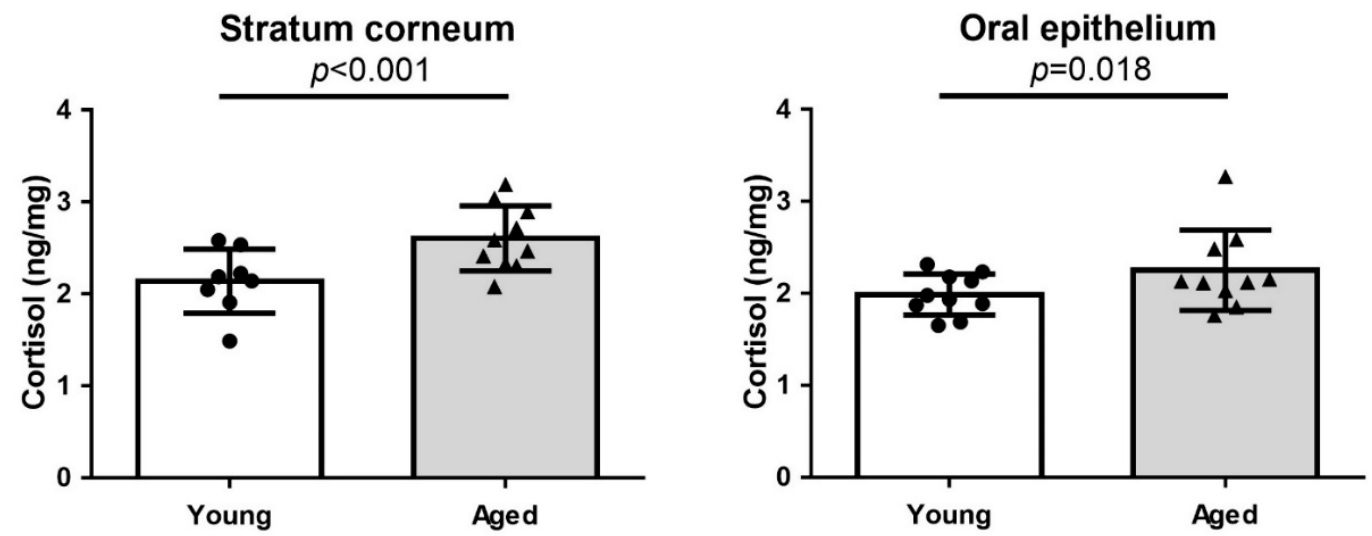

Figure 1. Cortisol levels in the stratum corneum (SC) (left) and oral epithelium (right) collected from young and aged participants ( $\mathrm{n}=10$ each). The cortisol levels both in the SC of the forearms and in the oral epithelium of the buccal mucosa were significantly higher in the aged group than in the young group. The data are presented as the means $\pm \mathrm{SD}$.

\subsection{Increased $11 \beta-H S D 1$ Expression in the Skin of Aged Hairless Mice}

The immunohistochemical (IHC) staining revealed higher 11 $\beta$-HSD1 expression in the skin of aged hairless mice than in that of young mice (Figure 2a). In particular, high $11 \beta$-HSD1 expression was observed in the basal layer of the epidermis and dermis as well as in the SC. The semiquantitative analysis also showed significantly higher 11 $\beta$-HSD1 expression in the aged skin (3.167 \pm 0.4082 vs. $1.5 \pm 0.5477, p<0.001$; Figure $2 b)$.

(a)
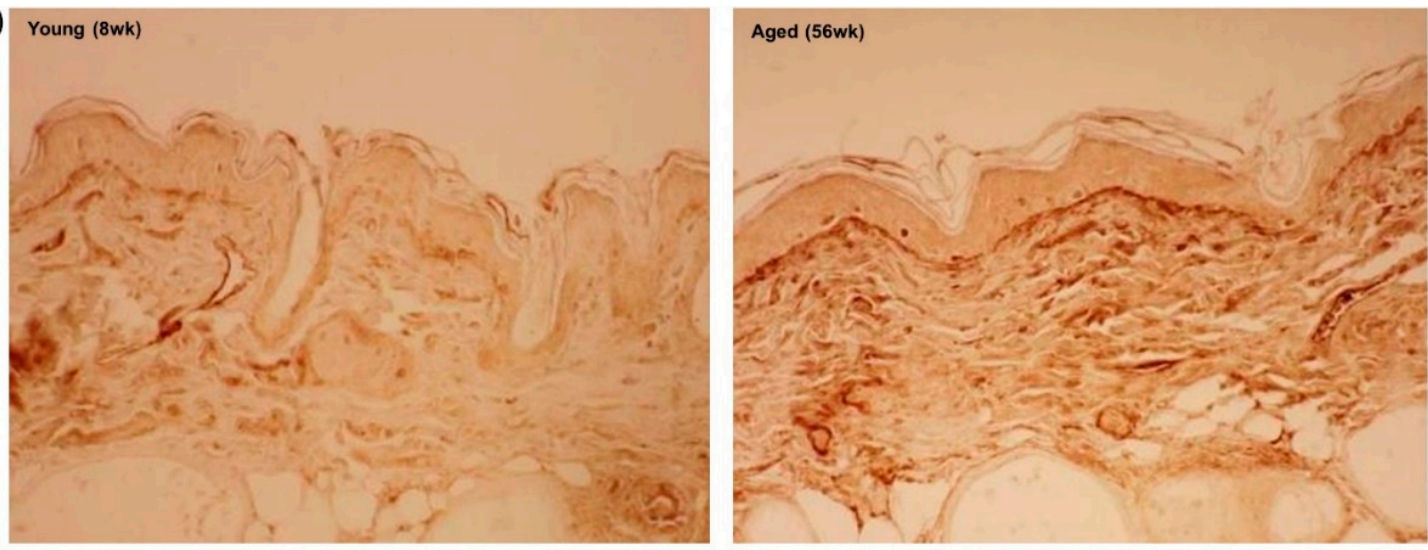

(b)

$11 \beta-H S D 1$ expression

$p<0.001$

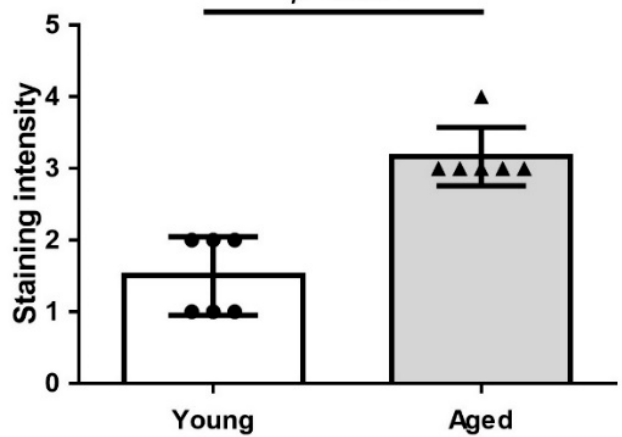

Figure 2. Immunohistochemical (IHC) staining and semi-quantitative analysis of the $11 \beta$-hydroxysteroid dehydrogenase type $1(11 \beta-H S D 1)$ expression in the skin of young and aged hairless mice. (a) The 11 $\beta$-HSD1 expression is higher in the skin of aged hairless mice than in that of young mice. (b) The results of the semi-quantitative analysis, showing significantly higher $11 \beta-H S D 1$ expression in the aged skin than in the young skin ( $\mathrm{n}=6$ each). The data are presented as the means \pm SD. 


\subsection{Deterioration of Skin Barrier Function in Aged Hairless Mice}

We evaluated the skin barrier function of young (8-week-old) and aged (56-weekold) hairless mice (Figure 3). The aged mice featured significantly higher transepidermal water loss (TEWL; $9.630 \pm 2.1273$ vs. $\left.5.980 \pm 1.6571 \mathrm{~g} /\left[\mathrm{m}^{2} \cdot \mathrm{h}\right], p=0.016\right)$ and lower SC hydration ( $27.09 \pm 6.626$ vs. $45.64 \pm 6.409$ arbitrary units $(\mathrm{AU}), p=0.016)$ than the young mice. Nonetheless, we detected no difference in the SC integrity between the groups $\left(2.448 \pm 1.3049\right.$ vs. $\left.3.195 \pm 1.9749 \mathrm{~g} /\left[\mathrm{m}^{2} \cdot \mathrm{h}\right], p=0.999\right)$.
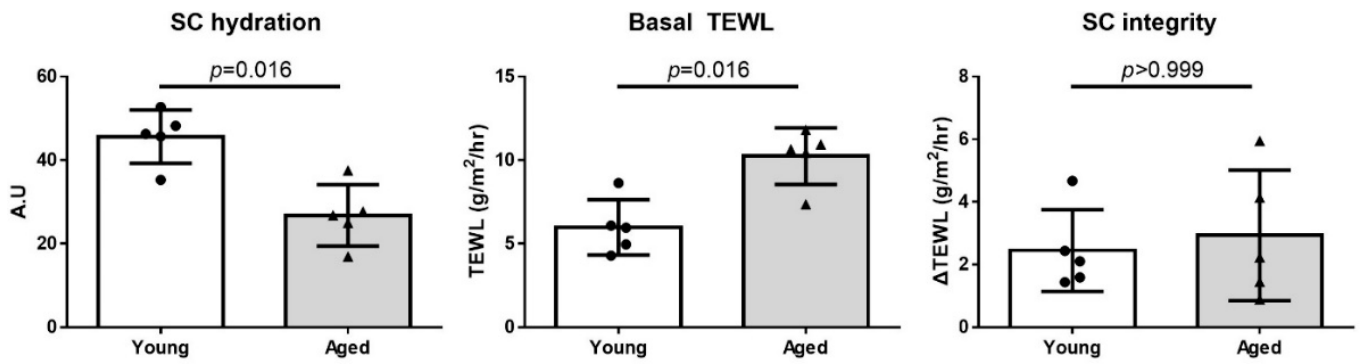

Figure 3. Skin barrier function in the skin of young and aged hairless mice. The aged mice had lower SC hydration and higher basal TEWL, but there was no difference in SC integrity between the groups. SC integrity was defined as the change in TEWL after 15 rounds of D-Squame disc tape stripping. The data are presented as the means \pm SD. SC, stratum corneum; TEWL, transepidermal water loss.

\subsection{Increased Serum Inflammatory Cytokine Levels in Aged Hairless Mice}

We measured the serum cytokine levels in the young and aged hairless mice using enzyme-linked immunosorbent assays (ELISAs). The levels of inflammatory cytokines, including interleukin (IL) 31 , IL-1 $\alpha$, IL-4, and tumor necrosis factor- $\alpha$ (TNF- $\alpha$ ) were significantly higher in the serum of aged mice (Figure 4).

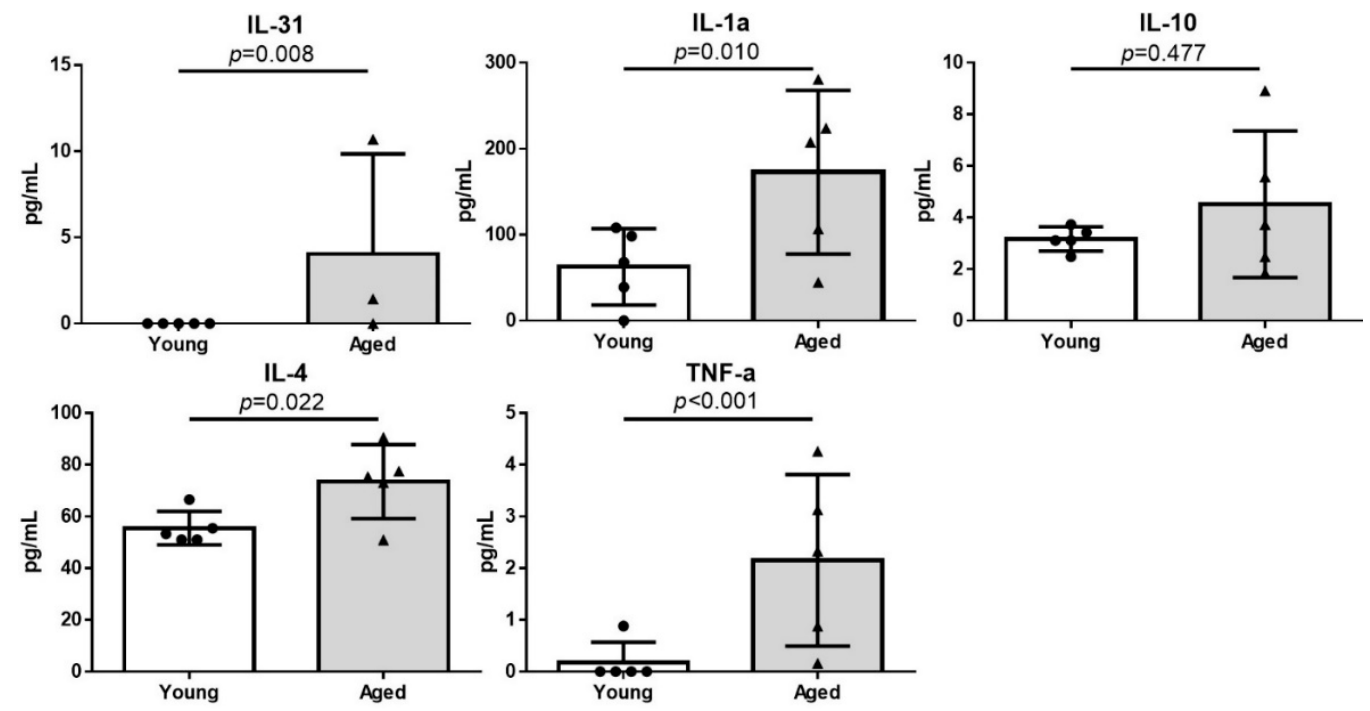

Figure 4. Inflammatory cytokine levels in the serum of young and aged hairless mice. Concentrations of inflammatory cytokines were significantly higher in the serum of aged mice. The data are presented as the means \pm SD. IL, interleukin; TNF, tumor necrosis factor.

2.5. Reduced SC Corticosterone Concentration in Aged 11 $\beta-H S D 1$ (HSD11B1) Knockout (KO) Mice and Aged 11 $\beta$-HSD1 Inhibitor (INHI)-Treated Wild-Type (WT) Mice

The SC corticosterone levels were the highest in the aged WT mice $(5461.94 \pm$ $1465.21 \mathrm{ng} / \mathrm{mL}$ ). Compared to these, the SC corticosterone levels were lower in the young WT mice $(4244.20 \pm 1741.36 \mathrm{ng} / \mathrm{mL}, p=0.022)$ and the aged HSD11B1 KO mice $(3987.51 \pm 922.88 \mathrm{ng} / \mathrm{mL}, p=0.069)$. The SC corticosterone levels were also low in the 
aged WT mice treated topically with INHI $(3373.46 \pm 333.61, p=0.008)$. The reduction in the SC corticosterone level by topical INHI treatment was rather modest in young WT mice (Figure 5a and Table S1).

(a)

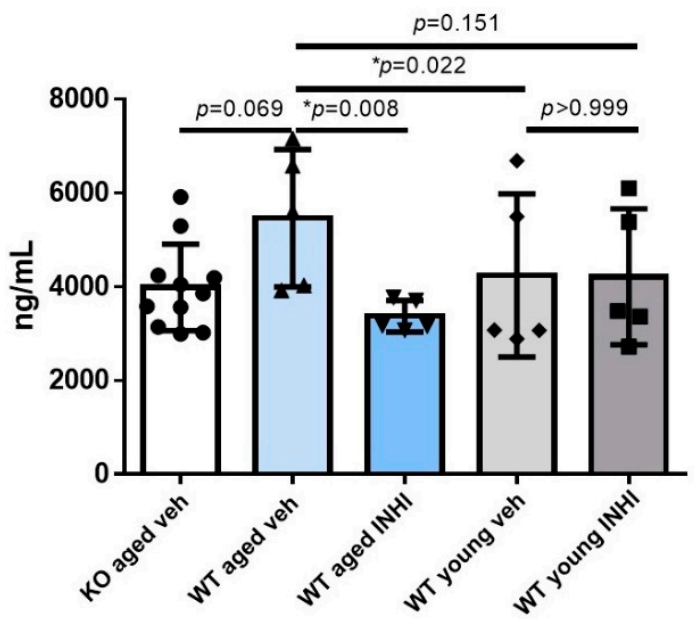

(b)

\section{Corneodesmosome density}

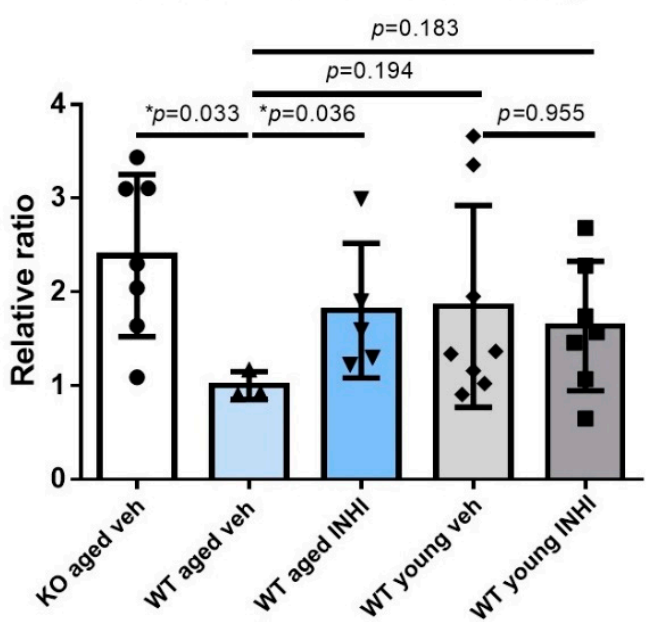

Figure 5. Stratum corneum (SC) corticosterone and corneodesmosome (CD) density in HSD11B1 knock-out (KO) and wild type (WT) mice. (a) The SC corticosterone level was the highest in the aged WT mice. Both the HSD11B1 KO and treatment with the 11 $\beta-H S D 1$ inhibitor (INHI) decreased the SC corticosterone level in the aged mice. (b) The CD density was the highest in the aged KO mice. The aged WT mice showed lower CD density than the young WT mice. INHI treatment increased the CD density in the aged WT mice. The data are presented as the means \pm SD. ${ }^{*}$ statistically significant $(p<0.05)$; veh, vehicle.

2.6. Decreased Corneodesmosome (CD) Density in WT Aged Mice Compared to That in Aged HSD11B1 KO Mice and Aged INHI-Treated WT Mice

The CD density was measured by electron microscopic (EM) imaging to evaluate the SC integrity (Figure 5b and Table S2). The calculation of the CD density ratio in aged WT mice showed a significantly higher CD density in the aged KO mice (the ratio of 2.39, $p=0.033)$. The CD density in the young WT mice was higher than that in the aged WT mice (ratio $=1.85, p=0.194$ ); the topical INHI application led to the recovery of the CD density in the aged WT mice (ratio $=1.80, p=0.036$ ). The topical INHI application did not affect the young WT mice.

\subsection{Recovery of the SC Lipid Levels in WT Aged Mice upon the Topical INHI Treatment}

The levels of all three major types of SC lipids (ceramide, cholesterol, and free fatty acids (free FAs)) were significantly lower in the aged WT mice than in the young WT mice after treatment with the vehicle $(p<0.05$ in each case; Figure 6a and Tables S3-S5). Topical treatment with INHI led to the recovery of the levels of all three lipid types in both aged and young WT mice. In particular, the aged mice showed significantly higher ceramide and total FA levels upon INHI treatment ( $p=0.008$ in each case), though the changes in cholesterol levels were not significant $(p=0.095)$. The extent of this increase was less drastic in young mice. There was also no difference between the levels of all three lipid types in the aged HSD11B1 KO and aged WT mice. Ceramide levels were similarly lower in both the WT and KO aged mice regardless of the number of chains (Figure 6b). The free FA levels were also lower, regardless of saturation, in aged mice (Figure 6c). 


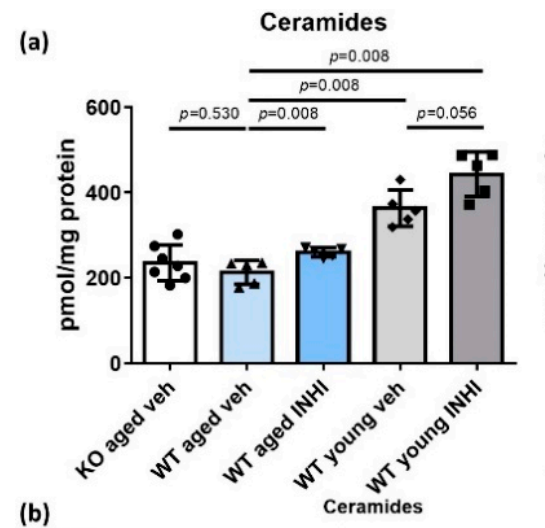

(b)

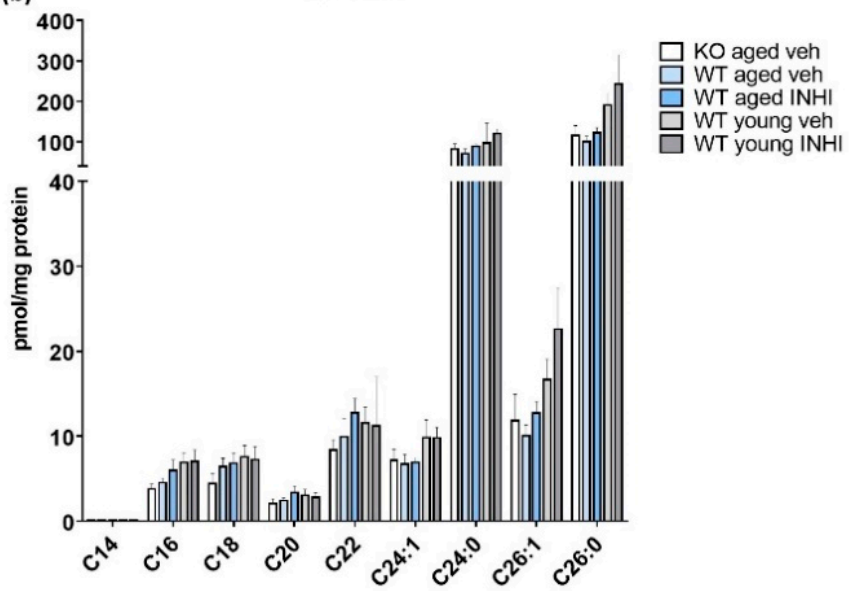

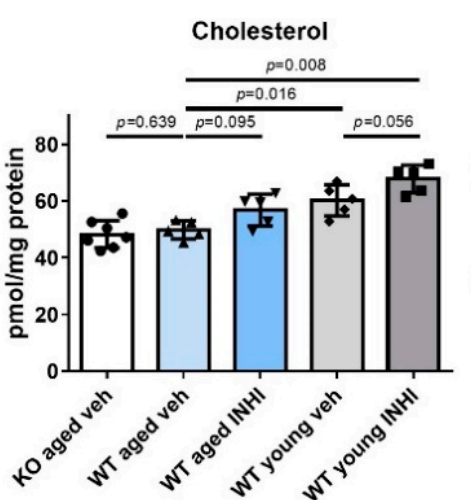

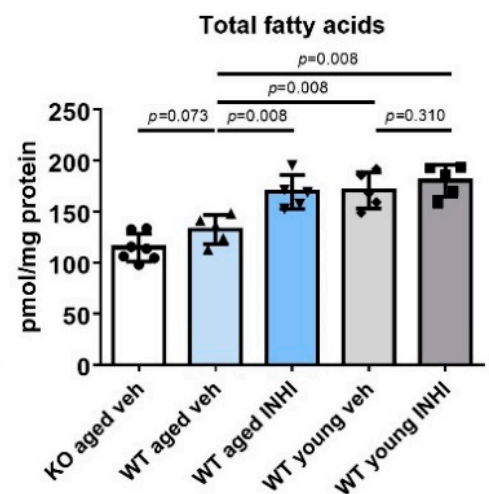

(c) Fatty acids

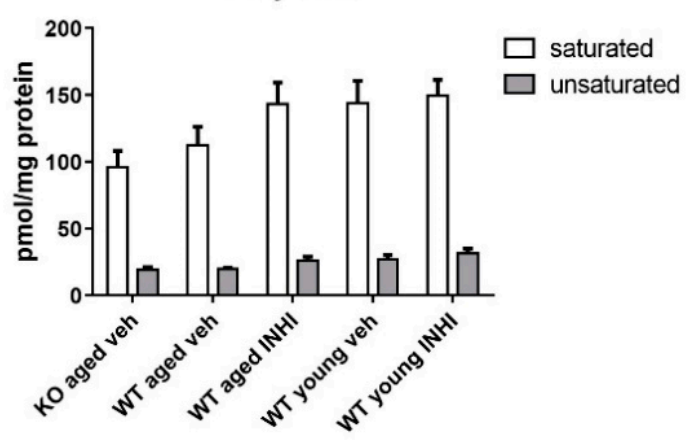

Figure 6. Lipid analysis of HSD11B1 knock-out (KO) and wild type (WT) mice. (a) The levels of three major types of SC lipids (ceramide, cholesterol, and free fatty acids (free FAs)) were significantly lower in aged WT mice than in young WT mice after treatment with the vehicle $(p<0.05$ in each case). Topical INHI treatment led to a recovery of the levels of all three lipid types in both the aged and young WT mice. The levels of ceramide and total FAs increased significantly in the aged mice after INHI treatment (each $p=0.008)$, whereas the cholesterol level did not $(p=0.095)$. The extent of these increases was smaller among young mice. There was no difference between the levels of all three lipid types in the aged HSD11B1 KO mice and aged WT mice. (b) The ceramide levels were evenly reduced in the aged WT and aged HSD11B1 KO mice regardless of the number of carbons in the fatty acyl chains. (c) In the aged mice, free FA levels were also low regardless of the presence of saturation. The data are presented as the means \pm SD. INHI, 11ß-HSD1 inhibitor; veh, vehicle.

\section{Discussion}

Increased active GC levels reportedly deteriorate the skin barrier function by inhibiting keratinocyte differentiation and proliferation [41,42], lipid synthesis [9], and serine protease activation via an increase in the skin surface $\mathrm{pH}[43,44]$. The adverse changes in the function and structure of the aged skin may be due to the increased local GC production, which is largely mediated by $11 \beta$-HSD1 [14,29]. The $11 \beta$-HSD1 expression reportedly increases with aging $[14,15,40]$, and the present study provides evidence regarding the fact that the cutaneous activation of endogenous GCs is associated with skin aging, mediated by an increase in $11 \beta-H S D 1$ expression.

In this study, we detected increased cortisol levels in both the SC and the oral mucosal cells in the aged participants (Figure 1). In our previous study on psychological stressinduced skin barrier damage [45], elevated SC cortisol levels positively correlated with the extent of skin barrier dysfunction and 11ß-HSD1 concentration in the oral mucosa. Therefore, in the present study, cortisol levels were measured in both the SC and the oral mucosa. Nonetheless, we noted a lack of correlation between the SC cortisol and the oral epithelial cortisol levels. Moreover, the 11 $\beta-H S D 1$ level in the oral mucosa showed no agedependency (data not shown). As 11 $\beta$-HSD1 is expressed predominantly in the suprabasal layer of the epidermis and dermis, this epidermal expression could be detected only by a 
whole-epidermis skin biopsy [45]. In the mouse skin IHC staining assay reported in this study, the 11 $\beta$-HSD1 expression was observed mainly in the basal layer of the epidermis and throughout the dermis, which was more evident in aged mice (Figure 2). We believe that the detected increase in the cortisol levels in the elderly and the higher 11 $\beta$-HSD1 expression in the aged murine skin validate the first part of our hypothesis.

When we explored the differences in skin barrier function between young and aged hairless mice (Figure 3), we noted a significant reduction in SC hydration and an increase in the basal TEWL in aged mice, consistent with results from previously published studies [46]. In contrast, the SC integrity showed a statistically non-significant decrease. These observations could be explained by the fact that the aged mice used in this experiment were 56-week-old, i.e., they were relatively young compared to those used in another study [47].

The levels of inflammatory cytokines, such as IL- $1 \alpha$, IL-4, IL-31, and TNF- $\alpha$, were significantly elevated in the serum of aged hairless mice, compared to those in the serum of young mice (Figure 4). This result is in good agreement with that of another previous study [48], which showed that sustained abnormal epidermal permeability increases the levels of inflammatory cytokines, which might render the elderly susceptible to chronic inflammatory diseases. A prolonged reduction in SC hydration also contributes to the aggravation of cutaneous inflammation, independently of the barrier disruption [49,50].

The observed increase in the SC corticosterone concentration in aged WT mice and its decrease in the aged HSD11B1 KO mice and aged INHI-treated WT mice further support our hypothesis and validate our experiments (Figure 5a). The inconspicuous changes in the SC corticosterone levels upon the INHI treatment in young WT mice may be due to their good functional health.

The levels of all three major types of SC lipids, including ceramide, cholesterol, and free FAs, proved to be significantly lower in the aged mice than in the young mice. These lipids are the main components important for not only the epidermal barrier formation, but also the maintenance of barrier function [51]. Therefore, the changes in their profiles could correlate with an impaired skin barrier function [52]. The levels of both long- and short-chained ceramides, were lower (to a similar extent) in the aged mice. Furthermore, the levels of both saturated and unsaturated FA levels showed a decrease (to similar extents) in the aged mice (Figure 6). These observations are consistent with those of other studies $[53,54]$. The detected increase in the SC lipid concentrations in the aged INHItreated mice, compared to that in the vehicle-treated group (along with significant ceramide and FA upregulation and a slight, though non-significant, increase in the cholesterol levels) validates our hypothesis. Our hypothesis also predicted higher SC lipid levels in the aged HSD11B1 KO mice than in the aged WT mice, but this prediction was found to be incorrect, probably because $H S D 11 B 1 \mathrm{KO}$ mice can produce sufficient compensatory cortisol in the blood to inhibit epidermal lipid synthesis. The inconspicuous changes in the SC lipid concentrations after the treatment of young WT mice with INHI can be ascribed to the health of the latter, as mentioned earlier.

Intrinsic and extrinsic aging-related epidermal thinning reduces the skin barrier function [55], thereby rendering the skin susceptible to daily external physical or chemical irritation. Epidermal stressors can induce inflammatory cytokine production [48], affecting steroid synthesis in the skin [56,57] and activating the HPA axis [58-60]. Local GC activation is needed to control this inflammatory trend in the aged skin, similar to the case for the active GC and $11 \beta$-HSD1 level increase in the wounded skin [33]. In addition, growth hormone, which inhibits 11 $\beta-H S D 1$ activity, is downregulated with age [61]. Eventually, local GC activation induced by the increase in the 11 $\beta$-HSD1 levels in the aged skin contributes to the skin barrier impairment associated with the disrupted homeostatic responses of the aged skin.

In our previous experiments performed using mice, the male mice fought and damaged the skin of each other during the breeding process; this rendered the optimal control set-up difficult to establish. This problem was solved by using only female mice, which yielded reliable results. Therefore, this study included only female subjects. Although sex- 
dependent cortisol level variations may also need to be considered [62,63], we used only female subject to set up good controls and ease the comparison and result interpretation processes.

We believe that our results validate the hypothesis that increased 11ß-HSD1 expression and the subsequent GC level increase could contribute to the deterioration of barrier function in the aged skin. In this study, we observed that active GCs (such as cortisol or corticosterone) and 11 $\beta$-HSD1 were upregulated in the aged skin. A reduced epidermal permeability barrier, including lower SC lipid levels, was also observed in the aged skin. Epidermal lipid amounts were increased in WT mice upon the INHI treatment, compared to the case for the mice in the vehicle group. Therefore, we could conclude that increased $11 \beta-H S D 1$ expression in the aged skin could increase active-GC levels, which, in turn, reduce the SC lipid levels and lead to the deterioration of the epidermal permeability barrier. These results should encourage further research and development of topical or systemic drugs that inhibit $11 \beta-H S D 1$ activity in the aging skin.

\section{Materials and Methods}

\subsection{The Human Experiment}

The clinical study protocol was approved by the Institutional Review Board of the Wonju Severance Christian Hospital (CR317026) and was performed in accordance with their guidelines. Informed consent was obtained from all participants. Ten healthy young ( $<25$ years old; mean age, 21.6 years) and ten aged ( $>60$ years old; mean age, 65.9 years) women were recruited for the study. The cortisol levels in their SC and oral epithelium were measured.

\subsection{The Animal Experiment}

The animal study protocol was approved by the Institutional Animal Care and Use Committee of the Yonsei University Wonju College of Medicine (YWC-150303-1) and was performed in accordance with the ARRIVE guidelines. Female hairless mice $(h r / h r)$ were purchased from OrientBio (Seongnam, Republic of Korea). Experiments were conducted on five young (8-weeks-old) and five aged (56-week-old) female mice. Skin barrier function, serum cytokine levels, and 11 $\beta$-HSD1 expression (via IHC) were measured. Additionally, 8and 56-week-old HSD11B1 KO mice and their WT counterparts (C57BL/6) were subjected to the following experiments. Either vehicle (dimethyl sulfoxide, DMSO) or INHI (38558, Merck, Readington Township, NJ, USA) dissolved in the vehicle was applied onto the backs of the mice twice a day for 10 days. The experimental groups were as follows: group $1, H S D 11 B 1 \mathrm{KO}$ aged mice treated with vehicle $(\mathrm{n}=11)$; group 2, WT aged mice treated with vehicle $(n=5)$; group 3 , WT aged mice treated with INHI $(n=5)$; group 4 , WT young mice treated with vehicle $(n=5)$; and group 5 , WT young mice treated with INHI $(n=5)$. After 10 days of treatment, the SC corticosterone levels were measured, the CD density was determined by EM, and the epidermal lipid levels were analyzed.

\subsection{Preparation of $11 \beta-H S D 1$ KO Mice}

Global HSD11B1 KO mouse embryos were obtained from Professor Gareth G. Lavery (University of Birmingham, UK). Clones of the HSD11B1 KO gene were injected into C57BL/ 6 blastocysts according to a previous report [64]. The embryos were transferred into pseudo-pregnant C57BL/6 female mice, and heterozygous mice were generated. To confirm the germline transmission of the $\mathrm{KO}$ allele, a conventional polymerase chain reaction was carried out. The following primers were employed in multiplex mode: P1, 5'-GGGAGCTTGCTTACAGCATC-3'; P2, 5'-CATTCTCAAGGTAGATTGAACTCTG-3'; and P3, 5'-TCCATGCAATCAACTTCTCG-3'. Primers P2 and P3 yielded a band of $139 \mathrm{bp}$, indicating the presence of the WT allele. Amplicons representing the amplification of the DNA fragment located between P1- and P3-binding sites were not detected owing to the distance between these primers. In the $\mathrm{KO}$ allele, a P2- binding site was removed to ensure proximity between the P1- and P3-binding sites, resulting in the generation of a 
$242 \mathrm{bp}$ amplicon for the detection of the WT, heterozygote, and homozygote. Homozygous HSD11B1 KO mice were obtained after several subsequent breeding steps.

\subsection{Quantification of Cortisol and Corticosterone by ELISA}

We collected human SC samples from the forearms of our participants by stripping off D-Squame disc tape (CuDerm, Dallas, TX, USA) from their skin. Mucosal epithelial samples were collected from the buccal mucosa using Isohelix buccal swabs (Cell Projects, Kent, UK). SC samples of dorsal skin were collected from the HSD11B1 KO and WT mice by stripping ff D-Squame disc tapes from their skin before they were euthanized. The samples were placed in $500 \mu \mathrm{L}$ of lysis buffer, vortexed, and incubated overnight at $4{ }^{\circ} \mathrm{C}$. Cortisol and corticosterone levels in the obtained protein extracts were measured using the corresponding ELISA kits (Merck Millipore, Darmstadt, Germany) [45].

\subsection{Measurement of Skin Barrier Function}

Skin barrier function was assessed as the basal TEWL, SC hydration, and SC integrity (defined as changes in TEWL after 15 rounds of D-Squame disc tape stripping) of the dorsal skin of hairless mice. The TEWL was quantified with a Tewameter TM 210 (Courage and Khazaka Electronic GmbH, Cologne, Germany). SC hydration was measured using a Corneometer CM 850 (Courage and Khazaka) [65,66].

\subsection{IHC Staining and Semi-Quantitative Analysis of $11 \beta-H S D 1$}

Dorsal skin samples from young and aged hairless mice were immunohistochemically stained for 11 $\beta$-HSD1 [45]. Briefly, a primary antibody against 11 $\beta$-HSD1 (Santa Cruz Biotechnology, Santa Cruz, CA, USA) was added to $4 \mu \mathrm{m}$-thick paraffin-embedded skin tissue sections, followed by incubation overnight at $4{ }^{\circ} \mathrm{C}$. After three cycles of washing, the tissue sections were incubated with the appropriate secondary antibody for $30 \mathrm{~min}$ at room temperature $\left(22-26{ }^{\circ} \mathrm{C}\right)$. Antigen-antibody complexes were visualized by staining with the ABC-HRP Kit (Vector Lab, Burlingame, CA, USA), and counterstaining was performed with hematoxylin $[45,67]$. This procedure was followed by a semi-quantitative analysis of staining intensity in the tissue sections stained for $11 \beta$-HSD1. The intensity was classified as follows: 4 , marked; 3 , moderate; 2 , slight; and 1, basal.

\subsection{Serum Cytokine Level Assays}

In hairless mice, the serum levels of cytokines IL- $1 \alpha$, IL-4, IL-10, and IL-31, and TNF- $\alpha$ were measured using a bead-based multiplex immunoassay. Serum samples were centrifuged at $2000 \times g$ for $20 \mathrm{~min}$ to remove debris. Then, $75 \mu \mathrm{L}$ of each serum sample and $75 \mu \mathrm{L}$ of calibrator diluent RD6-52 were mixed at a 2-fold dilution. The serum levels of IL-1 $\alpha$, IL-4, IL-10, IL-31, and TNF- $\alpha$ were measured using the Magnetic Luminex Screening Assay Kit (R\&D Systems, Minneapolis, MN, USA). The samples and the antibody cocktail were mixed and incubated for $2 \mathrm{~h}$ at room temperature $\left(22-26^{\circ} \mathrm{C}\right)$, followed by analysis on a Luminex 100 device (Luminex, Austin, TX, USA).

\subsection{Quantitative EM}

Skin biopsy samples were collected from HSD11B1 KO mice and WT mice. The samples were pulverized into pieces less than $0.5 \mathrm{~mm}^{3}$, fixed overnight in modified Karnovsky's fixative, and post-fixed in $2 \%$ aqueous osmium tetroxide containing $1.5 \%$ potassium ferrocyanide, similar to the protocols described in previous reports $[11,68]$. Next, the samples were dehydrated in ethanol and embedded in an Epon-epoxy mixture. Ultrathin skin sections were examined under a transmission electron microscope (JEM-1200EXII, JEOL, Tokyo, Japan) operated at $80 \mathrm{kV}$.

For the quantitative EM analysis of the $C D$, its densities in the EM images were analyzed via an objective method to exclude subjective bias. To evaluate $C D$ density, which reflects SC integrity, we determined the $\mathrm{CD}$ length randomly from the first and second cell 
layers of the lower SC. The ratio of the total length of the $\mathrm{CD}$ to the total length of cornified envelopes in the lower SC was then calculated [11,69].

\subsection{Lipid Analysis in the SC}

Murine SC samples were collected by stripping off the D-Squame tape applied onto the back of the mice. SC samples were harvested from these D-Squame tapes and lysed in radioimmunoprecipitation assay buffer, and next, sphingolipids were extracted as per the procedures we have described previously $[70,71]$. The extracted lipids were dried in a vacuum system (Vision, Seoul, Republic of Korea), re-dissolved in methanol, and analyzed by liquid chromatography-electrospray ionization-tandem mass spectrometry (LC-ESI-MS/MS; API 3200 QTRAP mass; AB/Sciex, Framingham, MA, USA) in the selective ion monitoring mode. The ceramide MS/MS transitions $(\mathrm{m} / \mathrm{z})$ were $510 \rightarrow 264$ for C14-ceramide, $538 \rightarrow 264$ for C16-ceramide, $552 \rightarrow 264$ for C17-ceramide, $566 \rightarrow 264$ for C18-ceramide, $594 \rightarrow 264$ for C20-ceramide, $648 \rightarrow 264$ for C24:1-ceramide, $650 \rightarrow 264$ for C24-ceramide, $676 \rightarrow 264$ for C26:1-ceramide, and $678 \rightarrow 264$ for C26-ceramide.

To measure the free-cholesterol and free-FA levels, lipid extraction was performed using by the Folch method, with minor modifications [72-74]. Briefly, the SC tissues on the D-Squame tapes were lysed and sonicated in methanol-chloroform $(1: 2, v / v)$ containing butylated hydroxytoluene $(500 \mu \mathrm{g} / \mathrm{mL})$, followed by the addition of $500 \mathrm{pmol}$ of docosahexaenoic acid and cholesterol- $\mathrm{d}_{6}$ as an internal standard. The extracted lipids were dried in the vacuum system, re-dissolved in methanol, and analyzed via LC-ESI-MS/MS, which was operated in the selective ion monitoring mode. First, free cholesterol and FAs were separated by reverse-phase high-performance liquid chromatography (a NANOSPACE SI-2 HPLC system equipped with an HTS autosampler Z, Shiseido, Tokyo, Japan) on a Kinetex C18 column $(2.1 \times 50 \mathrm{~mm}$, internal diameter: $2.6 \mu \mathrm{m}$; Phenomenex, St. Louis, MO, USA), as described in previous studies [74,75]. The FA MS/MS transitions $(m / z)$ were $227 \rightarrow 183$ for C14:0 FA, $253 \rightarrow 209$ for C16:1 FA, $255 \rightarrow 211$ for C16:0 FA, $277 \rightarrow 233$ for C18:3 FA, $279 \rightarrow 235$ for C18:2 FA, $281 \rightarrow 237$ C18:1 FA, $283 \rightarrow 239$ C18:0 FA, 303 $\rightarrow 259$ for C20:4 FA, 311 $\rightarrow 267$ for C20:0 FA, 337 $\rightarrow 293$ for C22:1 FA, 339 $\rightarrow 295$ for C22:0 FA, $365 \rightarrow 321$ for C24:1 FA, and $367 \rightarrow 323$ for C24 FA. The MS/MS transitions $(\mathrm{m} / \mathrm{z})$ were $369.3 \rightarrow 161.5$ for cholesterol, $369.3 \rightarrow 147.1$ for free cholesterol, and $374.4 \rightarrow 152.7$ for cholesterol- $\mathrm{d}_{6}$. All data were acquired using the Analyst 1.5.1 software (Applied Biosystems, Foster City, CA, USA).

\subsection{Statistical Analysis}

Either the Student's t-test or the Mann-Whitney U test was performed, as appropriate, to analyze the differences between two groups using the GraphPad Prism 5 software (GraphPad Software, La Jolla, CA, USA). We performed two-way analysis of variance (ANOVA) followed by the Dunn-Bonferroni test to investigate the differences among multiple treatment groups. Statistical significance was set at $p<0.05$.

Supplementary Materials: The following are available online at https:/ /www.mdpi.com/article/10 $.3390 / \mathrm{ijms} 22115750 / \mathrm{s} 1$.

Author Contributions: Conceptualization, B.J.K. and E.H.C.; Data Curation, B.J.K.; Formal Analysis, B.J.K., K.-O.S. and K.P.; Funding Acquisition, E.H.C.; Investigation, B.J.K., N.R.L., C.H.L., Y.B.L., S.J.C., S.L., H.J.H. and E.K.; Methodology, B.J.K. and E.H.C.; Project Administration, E.H.C.; Resources, B.J.K., H.J.H., E.K. and G.G.L.; Supervision, E.H.C.; Validation, B.J.K., K.-O.S., K.P. and E.H.C.; Visualization, B.J.K. and H.J.H.; Writing-Original Draft Preparation, B.J.K.; Writing-Review and Editing, B.J.K. and E.H.C. All authors have read and agreed to the published version of the manuscript.

Funding: This work was supported by a grant from the National Research Foundation of Korea (NRF) funded by the Korea government (MEST; grant No. NRF-2018R1A2B2005002).

Institutional Review Board Statement: The study was conducted according to the guidelines of the Declaration of Helsinki, and approved by the Institutional Review Board of Wonju Severance Christian Hospital (CR317026) and Institutional Animal Care and Use Committee of Yonsei University Wonju College of Medicine (YWC-150303-1). 
Informed Consent Statement: Informed consent was obtained from all subjects involved in the study.

Data Availability Statement: The datasets generated and/or analyzed during the current study are available from the corresponding author upon reasonable request.

Conflicts of Interest: The authors declare no conflict of interest.

\section{References}

1. Cerimele, D.; Celleno, L.; Serri, F. Physiological changes in ageing skin. Br. J. Dermatol. 1990, 122 (Suppl. 35), 13-20. [CrossRef]

2. Tiganescu, A.; Tahrani, A.A.; Morgan, S.A.; Otranto, M.; Desmouliere, A.; Abrahams, L.; Hassan-Smith, Z.; Walker, E.A.; Rabbitt, E.H.; Cooper, M.S.; et al. 11beta-hydroxysteroid dehydrogenase blockade prevents age-induced skin structure and function defects. J. Clin. Investig. 2013, 123, 3051-3060. [CrossRef]

3. Kammeyer, A.; Luiten, R.M. Oxidation events and skin aging. Ageing Res. Rev. 2015, 21, 16-29. [CrossRef]

4. Tobin, D.J. Introduction to skin aging. J. Tissue Viability 2017, 26, 37-46. [CrossRef]

5. Keyes, B.E.; Liu, S.; Asare, A.; Naik, S.; Levorse, J.; Polak, L.; Lu, C.P.; Nikolova, M.; Pasolli, H.A.; Fuchs, E. Impaired epidermal to dendritic $t$ cell signaling slows wound repair in aged skin. Cell 2016, 167, 1323-1338.e1314. [CrossRef]

6. Ghadially, R.; Brown, B.E.; Hanley, K.; Reed, J.T.; Feingold, K.R.; Elias, P.M. Decreased epidermal lipid synthesis accounts for altered barrier function in aged mice. J. Investig. Dermatol. 1996, 106, 1064-1069. [CrossRef] [PubMed]

7. Angelova-Fischer, I.; Fischer, T.W.; Abels, C.; Zillikens, D. Accelerated barrier recovery and enhancement of the barrier integrity and properties by topical application of a ph 4 vs. A ph 5.8 water-in-oil emulsion in aged skin. Br. J. Dermatol. 2018, 179, 471-477. [CrossRef] [PubMed]

8. Biniek, K.; Kaczvinsky, J.; Matts, P.; Dauskardt, R.H. Understanding age-induced alterations to the biomechanical barrier function of human stratum corneum. J. Dermatol. Sci. 2015, 80, 94-101. [CrossRef] [PubMed]

9. Kao, J.S.; Fluhr, J.W.; Man, M.Q.; Fowler, A.J.; Hachem, J.P.; Crumrine, D.; Ahn, S.K.; Brown, B.E.; Elias, P.M.; Feingold, K.R. Shortterm glucocorticoid treatment compromises both permeability barrier homeostasis and stratum corneum integrity: Inhibition of epidermal lipid synthesis accounts for functional abnormalities. J. Investig. Dermatol. 2003, 120, 456-464. [CrossRef] [PubMed]

10. Denda, M.; Tsuchiya, T.; Elias, P.M.; Feingold, K.R. Stress alters cutaneous permeability barrier homeostasis. Am. J. Physiol. Regul. Integr. Comp. Physiol. 2000, 278, R367-R372. [CrossRef] [PubMed]

11. Choi, E.H.; Brown, B.E.; Crumrine, D.; Chang, S.; Man, M.Q.; Elias, P.M.; Feingold, K.R. Mechanisms by which psychologic stress alters cutaneous permeability barrier homeostasis and stratum corneum integrity. J. Investig. Dermatol. 2005, 124, 587-595. [CrossRef]

12. Jozic, I.; Stojadinovic, O.; Kirsner, R.S.; Tomic-Canic, M. Stressing the steroids in skin: Paradox or fine-tuning? J. Investig. Dermatol. 2014, 134, 2869-2872. [CrossRef]

13. Tampa, M.; Sarbu, M.I.; Mitran, M.I.; Mitran, C.I.; Matei, C.; Georgescu, S.R. The pathophysiological mechanisms and the quest for biomarkers in psoriasis, a stress-related skin disease. Dis. Markers 2018, 2018, 5823684. [CrossRef]

14. Tiganescu, A.; Walker, E.A.; Hardy, R.S.; Mayes, A.E.; Stewart, P.M. Localization, age- and site-dependent expression, and regulation of 11beta-hydroxysteroid dehydrogenase type 1 in skin. J. Investig. Dermatol. 2011, 131, 30-36. [CrossRef] [PubMed]

15. Terao, M.; Katayama, I. Local cortisol/corticosterone activation in skin physiology and pathology. J. Dermatol. Sci. 2016, 84, 11-16. [CrossRef] [PubMed]

16. Kinn, P.M.; Holdren, G.O.; Westermeyer, B.A.; Abuissa, M.; Fischer, C.L.; Fairley, J.A.; Brogden, K.A.; Brogden, N.K. Agedependent variation in cytokines, chemokines, and biologic analytes rinsed from the surface of healthy human skin. Sci. Rep. 2015, 5, 10472. [CrossRef] [PubMed]

17. Slominski, A.; Wortsman, J.; Tuckey, R.C.; Paus, R. Differential expression of hpa axis homolog in the skin. Mol. Cell Endocrinol. 2007, 265-266, 143-149. [CrossRef]

18. Bocheva, G.; Slominski, R.M.; Slominski, A.T. Neuroendocrine aspects of skin aging. Int. J. Mol. Sci. 2019, 20, 2798. [CrossRef] [PubMed]

19. Jozic, I.; Stojadinovic, O.; Kirsner, R.S.F.; Tomic-Canic, M. Skin under the (spot)-light: Cross-talk with the central hypothalamicpituitary-adrenal (hpa) axis. J. Investig. Dermatol. 2015, 135, 1469-1471. [CrossRef]

20. Wierzbicka, J.M.; Zmijewski, M.A.; Antoniewicz, J.; Sobjanek, M.; Slominski, A.T. Differentiation of keratinocytes modulates skin hpa analog. J. Cell Physiol. 2017, 232, 154-166. [CrossRef]

21. Slominski, A.; Wortsman, J. Neuroendocrinology of the skin. Endocr. Rev. 2000, 21, 457-487. [CrossRef]

22. Slominski, A.T.; Zmijewski, M.A.; Zbytek, B.; Tobin, D.J.; Theoharides, T.C.; Rivier, J. Key role of crf in the skin stress response system. Endocr. Rev. 2013, 34, 827-884. [CrossRef] [PubMed]

23. Slominski, A.; Zjawiony, J.; Wortsman, J.; Semak, I.; Stewart, J.; Pisarchik, A.; Sweatman, T.; Marcos, J.; Dunbar, C.; Turkey, R.C. A novel pathway for sequential transformation of 7-dehydrocholesterol and expression of the p450scc system in mammalian skin. Eur. J. Biochem. 2004, 271, 4178-4188. [CrossRef] [PubMed]

24. Slominski, R.M.; Tuckey, R.C.; Manna, P.R.; Jetten, A.M.; Postlethwaite, A.; Raman, C.; Slominski, A.T. Extra-adrenal glucocorticoid biosynthesis: Implications for autoimmune and inflammatory disorders. Genes Immun. 2020, 21, 150-168. [CrossRef] [PubMed] 
25. Tomlinson, J.W.; Walker, E.A.; Bujalska, I.J.; Draper, N.; Lavery, G.G.; Cooper, M.S.; Hewison, M.; Stewart, P.M. 11betahydroxysteroid dehydrogenase type 1: A tissue-specific regulator of glucocorticoid response. Endocr. Rev. 2004, 25, 831-866. [CrossRef]

26. Loerz, C.; Maser, E. The cortisol-activating enzyme 11beta-hydroxysteroid dehydrogenase type 1 in skeletal muscle in the pathogenesis of the metabolic syndrome. J. Steroid Biochem. Mol. Biol. 2017, 174, 65-71. [CrossRef]

27. Dammann, C.; Stapelfeld, C.; Maser, E. Expression and activity of the cortisol-activating enzyme 11beta-hydroxysteroid dehydrogenase type 1 is tissue and species-specific. Chem. Biol. Interact. 2019, 303, 57-61. [CrossRef]

28. Li, X.; Wang, J.; Yang, Q.; Shao, S. 11beta-hydroxysteroid dehydrogenase type 1 in obese subjects with type 2 diabetes mellitus. Am. J. Med Sci. 2017, 354, 408-414. [CrossRef]

29. Tiganescu, A.; Hupe, M.; Jiang, Y.J.; Celli, A.; Uchida, Y.; Mauro, T.M.; Bikle, D.D.; Elias, P.M.; Holleran, W.M. Uvb induces epidermal 11beta-hydroxysteroid dehydrogenase type 1 activity in vivo. Exp. Dermatol. 2015, 24, 370-376. [CrossRef]

30. Terao, M.; Murota, H.; Kimura, A.; Kato, A.; Ishikawa, A.; Igawa, K.; Miyoshi, E.; Katayama, I. 11beta-hydroxysteroid dehydrogenase- 1 is a novel regulator of skin homeostasis and a candidate target for promoting tissue repair. PLoS ONE 2011, 6, e25039. [CrossRef] [PubMed]

31. Matsumoto, A.; Murota, H.; Terao, M.; Katayama, I. Attenuated activation of homeostatic glucocorticoid in keratinocytes induces alloknesis via aberrant artemin production. J. Investig. Dermatol. 2018, 138, 1491-1500. [CrossRef]

32. Boudon, S.; Heidl, M.; Vuorinen, A.; Wandeler, E.; Campiche, R.; Odermatt, A.; Jackson, E. Design, synthesis, and biological evaluation of novel selective peptide inhibitors of 11beta-hydroxysteroid dehydrogenase 1. Bioorg. Med. Chem. 2018, 26, 5128-5139. [CrossRef]

33. Tiganescu, A.; Hupe, M.; Uchida, Y.; Mauro, T.; Elias, P.M.; Holleran, W.M. Increased glucocorticoid activation during mouse skin wound healing. J. Endocrinol. 2014, 221, 51-61. [CrossRef]

34. Williamson, S.; Merritt, J.; De Benedetto, A. Atopic dermatitis in the elderly: A review of clinical and pathophysiological hallmarks. Br. J. Dermatol. 2020, 182, 47-54. [CrossRef]

35. Norman, R.A. Xerosis and pruritus in the elderly: Recognition and management. Dermatol. Ther. 2003, 16, 254-259. [CrossRef] [PubMed]

36. Jafferany, M.; Huynh, T.V.; Silverman, M.A.; Zaidi, Z. Geriatric dermatoses: A clinical review of skin diseases in an aging population. Int. J. Dermatol. 2012, 51, 509-522. [CrossRef] [PubMed]

37. Lee, N.R.; Kim, B.J.; Lee, C.H.; Lee, Y.B.; Lee, S.; Hwang, H.J.; Kim, E.; Kim, S.H.; Lee, M.G.; Lee, S.E.; et al. Role of 11betahydroxysteroid dehydrogenase type 1 in the development of atopic dermatitis. Sci. Rep. 2020, 10, 20237. [CrossRef] [PubMed]

38. Boudon, S.M.; Vuorinen, A.; Geotti-Bianchini, P.; Wandeler, E.; Kratschmar, D.V.; Heidl, M.; Campiche, R.; Jackson, E.; Odermatt, A. Novel 11beta-hydroxysteroid dehydrogenase 1 inhibitors reduce cortisol levels in keratinocytes and improve dermal collagen content in human ex vivo skin after exposure to cortisone and uv. PLoS ONE 2017, 12, e0171079. [CrossRef]

39. Tiganescu, A.; Hupe, M.; Uchida, Y.; Mauro, T.; Elias, P.M.; Holleran, W.M. Topical 11beta-hydroxysteroid dehydrogenase type 1 inhibition corrects cutaneous features of systemic glucocorticoid excess in female mice. Endocrinology 2018, 159, 547-556. [CrossRef]

40. Terao, M.; Tani, M.; Itoi, S.; Yoshimura, T.; Hamasaki, T.; Murota, H.; Katayama, I. 11beta-hydroxysteroid dehydrogenase 1 specific inhibitor increased dermal collagen content and promotes fibroblast proliferation. PLoS ONE 2014, 9, e93051. [CrossRef]

41. Sheu, H.M.; Tai, C.L.; Kuo, K.W.; Yu, H.S.; Chai, C.Y. Modulation of epidermal terminal differentiation in patients after long-term topical corticosteroids. J. Dermatol. 1991, 18, 454-464. [CrossRef]

42. Sheu, H.M.; Lee, J.Y.; Kuo, K.W.; Tsai, J.C. Permeability barrier abnormality of hairless mouse epidermis after topical corticosteroid: Characterization of stratum corneum lipids by ruthenium tetroxide staining and high-performance thin-layer chromatography. J. Dermatol. 1998, 25, 281-289. [CrossRef]

43. Ali, S.M.; Yosipovitch, G. Skin ph: From basic science to basic skin care. Acta Derm. Venereol. 2013, 93, 261-267. [CrossRef] [PubMed]

44. Man, G.; Mauro, T.M.; Kim, P.L.; Hupe, M.; Zhai, Y.; Sun, R.; Crumrine, D.; Cheung, C.; Nuno-Gonzalez, A.; Elias, P.M.; et al Topical hesperidin prevents glucocorticoid-induced abnormalities in epidermal barrier function in murine skin. Exp. Dermatol. 2014, 23, 645-651. [CrossRef] [PubMed]

45. Choe, S.J.; Kim, D.; Kim, E.J.; Ahn, J.S.; Choi, E.J.; Son, E.D.; Lee, T.R.; Choi, E.H. Psychological stress deteriorates skin barrier function by activating 11beta-hydroxysteroid dehydrogenase 1 and the hpa axis. Sci. Rep. 2018, 8, 6334. [CrossRef]

46. Choi, E.H. Aging of the skin barrier. Clin. Dermatol. 2019, 37, 336-345. [CrossRef] [PubMed]

47. Choi, E.H.; Man, M.Q.; Xu, P.; Xin, S.; Liu, Z.; Crumrine, D.A.; Jiang, Y.J.; Fluhr, J.W.; Feingold, K.R.; Elias, P.M.; et al. Stratum corneum acidification is impaired in moderately aged human and murine skin. J. Investig. Dermatol. 2007, 127, $2847-2856$. [CrossRef]

48. Hu, L.; Mauro, T.M.; Dang, E.; Man, G.; Zhang, J.; Lee, D.; Wang, G.; Feingold, K.R.; Elias, P.M.; Man, M.Q. Epidermal dysfunction leads to an age-associated increase in levels of serum inflammatory cytokines. J. Investig. Dermatol. 2017, 137, 1277-1285. [CrossRef] [PubMed]

49. Ashida, Y.; Ogo, M.; Denda, M. Epidermal interleukin-1 alpha generation is amplified at low humidity: Implications for the pathogenesis of inflammatory dermatoses. Br. J. Dermatol. 2001, 144, 238-243. [CrossRef] 
50. Denda, M.; Sato, J.; Tsuchiya, T.; Elias, P.M.; Feingold, K.R. Low humidity stimulates epidermal DNA synthesis and amplifies the hyperproliferative response to barrier disruption: Implication for seasonal exacerbations of inflammatory dermatoses. J. Investig. Dermatol. 1998, 111, 873-878. [CrossRef]

51. Jia, Y.; Gan, Y.; He, C.; Chen, Z.; Zhou, C. The mechanism of skin lipids influencing skin status. J. Dermatol. Sci. 2018, 89, 112-119. [CrossRef]

52. van Smeden, J.; Bouwstra, J.A. Stratum corneum lipids: Their role for the skin barrier function in healthy subjects and atopic dermatitis patients. Curr. Probl. Dermatol. 2016, 49, 8-26. [CrossRef]

53. Zettersten, E.M.; Ghadially, R.; Feingold, K.R.; Crumrine, D.; Elias, P.M. Optimal ratios of topical stratum corneum lipids improve barrier recovery in chronologically aged skin. J. Am. Acad. Dermatol. 1997, 37, 403-408. [CrossRef]

54. Ghadially, R.; Brown, B.E.; Sequeira-Martin, S.M.; Feingold, K.R.; Elias, P.M. The aged epidermal permeability barrier. Structural, functional, and lipid biochemical abnormalities in humans and a senescent murine model. J. Clin. Investig. 1995, 95, 2281-2290. [CrossRef] [PubMed]

55. Chambers, E.S.; Vukmanovic-Stejic, M. Skin barrier immunity and ageing. Immunology 2020, 160, 116-125. [CrossRef]

56. Skobowiat, C.; Dowdy, J.C.; Sayre, R.M.; Tuckey, R.C.; Slominski, A. Cutaneous hypothalamic-pituitary-adrenal axis homolog: Regulation by ultraviolet radiation. Am. J. Physiol. Endocrinol. Metab. 2011, 301, E484-E493. [CrossRef] [PubMed]

57. Skobowiat, C.; Sayre, R.M.; Dowdy, J.C.; Slominski, A.T. Ultraviolet radiation regulates cortisol activity in a waveband-dependent manner in human skin ex vivo. Br. J. Dermatol. 2013, 168, 595-601. [CrossRef] [PubMed]

58. Slominski, A.T.; Zmijewski, M.A.; Plonka, P.M.; Szaflarski, J.P.; Paus, R. How uv light touches the brain and endocrine system through skin, and why. Endocrinology 2018, 159, 1992-2007. [CrossRef]

59. Skobowiat, C.; Postlethwaite, A.E.; Slominski, A.T. Skin exposure to ultraviolet b rapidly activates systemic neuroendocrine and immunosuppressive responses. Photochem. Photobiol. 2017, 93, 1008-1015. [CrossRef]

60. Skobowiat, C.; Slominski, A.T. Uvb activates hypothalamic-pituitary-adrenal axis in c57bl/6 mice. J. Investig. Dermatol. 2015, 135, 1638-1648. [CrossRef]

61. Moore, J.S.; Monson, J.P.; Kaltsas, G.; Putignano, P.; Wood, P.J.; Sheppard, M.C.; Besser, G.M.; Taylor, N.F.; Stewart, P.M. Modulation of 11beta-hydroxysteroid dehydrogenase isozymes by growth hormone and insulin-like growth factor: In vivo and in vitro studies. J. Clin. Endocrinol. Metab. 1999, 84, 4172-4177. [CrossRef] [PubMed]

62. Reschke-Hernandez, A.E.; Okerstrom, K.L.; Bowles Edwards, A.; Tranel, D. Sex and stress: Men and women show different cortisol responses to psychological stress induced by the trier social stress test and the iowa singing social stress test. J. Neurosci. Res. 2017, 95, 106-114. [CrossRef] [PubMed]

63. Roelfsema, F.; van Heemst, D.; Iranmanesh, A.; Takahashi, P.; Yang, R.; Veldhuis, J.D. Impact of age, sex and body mass index on cortisol secretion in 143 healthy adults. Endocr. Connect. 2017, 6, 500-509. [CrossRef] [PubMed]

64. Semjonous, N.M.; Sherlock, M.; Jeyasuria, P.; Parker, K.L.; Walker, E.A.; Stewart, P.M.; Lavery, G.G. Hexose-6-phosphate dehydrogenase contributes to skeletal muscle homeostasis independent of 11beta-hydroxysteroid dehydrogenase type 1. Endocrinology 2011, 152, 93-102. [CrossRef] [PubMed]

65. Hong, S.P.; Oh, Y.; Jung, M.; Lee, S.; Jeon, H.; Cho, M.Y.; Lee, S.H.; Choi, E.H. Topical calcitriol restores the impairment of epidermal permeability and antimicrobial barriers induced by corticosteroids. Br. J. Dermatol. 2010, 162, 1251-1260. [CrossRef]

66. Lee, H.J.; Yoon, N.Y.; Lee, N.R.; Jung, M.; Kim, D.H.; Choi, E.H. Topical acidic cream prevents the development of atopic dermatitis- and asthma-like lesions in murine model. Exp. Dermatol. 2014, 23, 736-741. [CrossRef]

67. Lee, H.J.; Lee, N.R.; Kim, B.K.; Jung, M.; Kim, D.H.; Moniaga, C.S.; Kabashima, K.; Choi, E.H. Acidification of stratum corneum prevents the progression from atopic dermatitis to respiratory allergy. Exp. Dermatol. 2017, 26, 66-72. [CrossRef]

68. Menon, G.K.; Feingold, K.R.; Elias, P.M. Lamellar body secretory response to barrier disruption. J. Investig. Dermatol. 1992, 98, 279-289. [CrossRef]

69. Choi, E.H.; Demerjian, M.; Crumrine, D.; Brown, B.E.; Mauro, T.; Elias, P.M.; Feingold, K.R. Glucocorticoid blockade reverses psychological stress-induced abnormalities in epidermal structure and function. Am. J. Physiol. Regul. Integr. Comp. Physiol. 2006, 291, R1657-R1662. [CrossRef]

70. Park, K.; Ikushiro, H.; Seo, H.S.; Shin, K.O.; Kim, Y.I.; Kim, J.Y.; Lee, Y.M.; Yano, T.; Holleran, W.M.; Elias, P.; et al. Er stress stimulates production of the key antimicrobial peptide, cathelicidin, by forming a previously unidentified intracellular s1p signaling complex. Proc. Natl. Acad. Sci. USA 2016, 113, E1334-E1342. [CrossRef] [PubMed]

71. Shin, K.O.; Lim, C.J.; Park, H.Y.; Kim, S.; Kim, B.; Lee, Y.; Chung, H.; Jeong, S.K.; Park, K.; Park, K. Activation of sirt1 enhances epidermal permeability barrier formation through ceramide synthase 2- and 3-dependent mechanisms. J. Investig. Dermatol. 2020. [CrossRef] [PubMed]

72. Della Corte, A.; Chitarrini, G.; Di Gangi, I.M.; Masuero, D.; Soini, E.; Mattivi, F.; Vrhovsek, U. A rapid lc-ms/ms method for quantitative profiling of fatty acids, sterols, glycerolipids, glycerophospholipids and sphingolipids in grapes. Talanta 2015, 140, 52-61. [CrossRef] [PubMed]

73. Folch, J.; Lees, M.; Sloane Stanley, G.H. A simple method for the isolation and purification of total lipides from animal tissues. J. Biol. Chem. 1957, 226, 497-509. [CrossRef] 
74. Perez-Navarro, J.; Da Ros, A.; Masuero, D.; Izquierdo-Canas, P.M.; Hermosin-Gutierrez, I.; Gomez-Alonso, S.; Mattivi, F.; Vrhovsek, U. Lc-ms/ms analysis of free fatty acid composition and other lipids in skins and seeds of vitis vinifera grape cultivars. Food Res. Int. 2019, 125, 108556. [CrossRef] [PubMed]

75. Hasan, M.; Siegmund, W.; Oswald, S. Rapid lc-ms/ms method for the determination of 4-hydroxycholesterol/cholesterol ratio in serum as endogenous biomarker for cyp3a activity in human and foals. J. Chromatogr. B Anal. Technol. Biomed. Life Sci. 2016, 1033-1034, 193-199. [CrossRef] [PubMed] 